\title{
Interdecadal change of summer precipitation over Eastern China around the late-1990s and associated circulation anomalies, internal dynamical causes
}

\author{
HUANG RongHui ${ }^{1,2 *}$, LIU Yong ${ }^{2} \&$ FENG Tao ${ }^{2}$ \\ ${ }^{1}$ State Key Laboratory of Numerical Modeling for Atmospheric Sciences and Geophysical Fluid Dynamics, Institute of Atmospheric Physics, \\ Chinese Academy of Sciences, Beijing 100029, China; \\ ${ }^{2}$ Center for Monsoon System Research, Institute of Atmospheric Physics, Chinese Academy of Sciences, Beijing 100190, China
}

Received August 20, 2012; accepted October 9, 2012; published online December 11, 2012

\begin{abstract}
Observational study indicated that the summer precipitation over Eastern China experienced a notable interdecadal change around the late-1990s. Accompanying this interdecadal change, the dominant mode of anomalous precipitation switched from a meridional triple pattern to a dipole pattern, showing a "south-flood-north-drought" structure (with the exception of the Yangtze River Valley). This interdecadal change of summer precipitation over Eastern China was associated with circulation anomalies in the middle/upper troposphere over East Asia, such as changes in winds and corresponding divergence, vertical motion and moisture transportation (divergence), which all exhibit remarkable meridional dipole structures. Furthermore, on the internal dynamic and thermodynamic aspects, the present study investigated the influence of the midtroposphere zonal and meridional flow changes over East Asia on the interdecadal change around the late-1990s. Results suggested that, during 1999-2010, the East Asia subtropical westerly jet weakened and shifted poleward, forming a meridional dipole feature in anomalous zonal flow. This anomalous zonal flow, on one hand, induced changes in three teleconnection patterns over the Eurasian continent, namely the "Silk Road" pattern along the subtropical upper troposphere westerly jet, the East Asia/Pacific (EAP) pattern along the East Asian coast, and the Eurasia (EU) pattern along the polar jet; on the other hand, it brought about cold advection over Northern China, and warm advection over Southern China in the mid-troposphere. Through these two ways, the changes in the zonal flow induced descent over Northern China and ascent over Southern China, which resulted in the anomalous "south-flood-north-drought" feature of the summer precipitation over Eastern China during 1999-2010.
\end{abstract}

summer precipitation, interdecadal change, features, causes, dynamics

Citation: Huang R H, Liu Y, Feng T. Interdecadal change of summer precipitation over Eastern China around the late-1990s and associated circulation anomalies, internal dynamical causes. Chin Sci Bull, 2013, 58: 1339-1349, doi: 10.1007/s11434-012-5545-9

China is located in the East Asia monsoon region, and the summer climate in China is seriously affected by the East Asia summer monsoon systems (EASM). Owing to the notable interdecadal variability of the EASM, the summer climate, especially the summer precipitation, of China reveals evident interdecadal variability [1-8]. Previous studies have pointed out several climate shifts in East Asia. For example, Yamamoto et al. [9] suggested a temperature jump around 1950 in northern Hemisphere (NH), especially over

*Corresponding author (email: hrh@mail.iap.ac.cn)
East Asia; Yan et al. [10] indicated that the summer precipitation in $\mathrm{NH}$ experienced a remarkable interdecadal change around the mid-1960s, and this climate change was accompanied by a decrease of summer precipitation in North China; Huang et al. [3] noted a significant interdecadal change in summer climate over East Asia around the late-1970s. Corresponding to the late 1970s' climate change, the summer precipitation over North China decreased, and that over the Yangtze-River Valley notably increased, which were different from those related to the mid-1960s climate change. Recently, Kwon et al. [11] and Ding et al. [12] revealed an 
interdecadal change of summer climate over East Asia around early-1990s. This climate change brought a notable increase to the summer precipitation over South China. Moreover, the studies of Zhu et al. [13] and Huang et al. [8] suggested that the summer climate over East Asia also experienced a distinct interdecadal change around the late1990s. Accompanying this change, precipitation decreased significantly over Northeast, North and Northwest China, and precipitation increased over the Huai River Valley.

Plenty of works had been devoted to the possible causes for these climate changes, especially for the late-1970s and early-1990s. Previous studies indicated that the interdecadal climate change over East Asia was not isolated but coherent with that over other areas over the global [2-7]. Huang et al. [3] attributed the distinct weakening of the EASM since the mid-/late-1970s to the sea surface temperature (SST) warming over equatorial eastern Pacific since the mid-/late-1970s, which showed an anomalous El Niño-like SST pattern. Since then, many studies analyzed the interdecadal changes of the atmospheric circulations over East Asia and pointed out the weakening of the EASM since the mid-/late-1970s. Results revealed that the persistent precipitation decrease over North China and the summer climate change over East Asia around the mid-/late-1970s may be closely related to southward/westward-shifting of the western north Pacific subtropical high $[4,5,14,15]$, the enhancement of the South Asia high [16,17], the troposphere cooling [18,19] and the enhancement and northward-shifting of subtropical westerly jet over East Asia [11]. Recently, Kwon et al. [11] stated that the interdecadal increase of summer precipitation over the South China around the early-1990s was accompanied by the weakening of the subtropical high-level westerly jet over East Asia, and studies of Ding et al. [20] and Wu et al. [21] attributed the interdecadal climate change around the early-1990s to the low-level anticyclonic circulation anomalies over the western north Pacific.

Huang et al. [8] demonstrated that the interdecadal change of summer precipitation over Eastern China (SPEA) was characterized mainly by the interdecadal change of the dominant modes of precipitation anomalies. They pointed out that the role of the dipole mode enhanced and showed that the dipole model is equally important as the triple mode of SPEA in the interdecadal anomaly pattern of SPEA during 1993-1998. In addition, their results primarily suggested that the dominate mode tended to change from the triple pattern to the dipole pattern since the late-1990s. With the goal of investigating the features of interdecadal change of the summer precipitation over Eastern China and the underlying possible causes in more detail and in a more systematic way, the present work studied the feature of the interdecadal change of the summer precipitation around the late 1990s and its association with the atmospheric circulation anomalies over East Asia by using the long-time observational precipitation datasets and monthly and daily NCEP/NCAR reanalysis datasets. On the dynamic and thermodynamic aspects, the internal dynamic causes for the interdecadal change around the late-1990s are explored through analyzing the middle/upper troposphere circulation changes. In particular, from the thermodynamic equation, we diagnose the role of the stationary and transient flow change on the midtroposphere temperature advection which will induce anomalous vertical motion and lead to the interdecadal change of the summer precipitation over Eastern China around the late-1990s.

\section{Data and methods}

The daily observational precipitation datasets of 756 weather stations in mainland China are used in this study, which is provided by the National Meteorological Information Center of Chinese Meteorological Administration. To achieve temporal continuity in terms of coverage from each station, 481 stations with period 1958-2010 are chosen from the data archive. The monthly and daily atmospheric fields used are from the National Centers for Environmental Prediction/National Center for Atmospheric Research reanalysis [22], which include horizontal winds, vertical velocity, temperature and specific humidity.

The common statistical techniques such as composite analysis, Student's $t$-test and Empirical orthogonal function (EOF) are employed in this study. And the abrupt change detection methods including moving $T$ test and Lepage test $[23,24]$ are applied as well. The climatology mean is defined as the average of 1971-2000.

\section{Features of the interdecadal change of the summer precipitation over eastern China in the late-1990s}

As the summer climate shift over Eastern China is mainly characterized as the precipitation variations [3], therefore, the interdecadal change of summer precipitation in China around the late-1990s is investigated in this section.

\subsection{Regional features of the interdecadal change of summer precipitation over Eastern China around the late-1990s}

In order to achieve the regional features of the interdecadal change of summer precipitation over Eastern China around the late-1990s, the rainfall datasets of 481 stations over Eastern China $\left(100^{\circ}-135^{\circ} \mathrm{E}\right)$, spanning the period $1958-$ 2010, are employed in the present study. The year-to-year precipitation anomaly percentages averaged over the four regions in Eastern China are shown in Figure 1. It can be seen that, on contrast to the summer precipitation during the 1990s, the precipitation during 1999-2010 revealed a significant decrease over Northeast China (NEC, Figure 1(a)) 

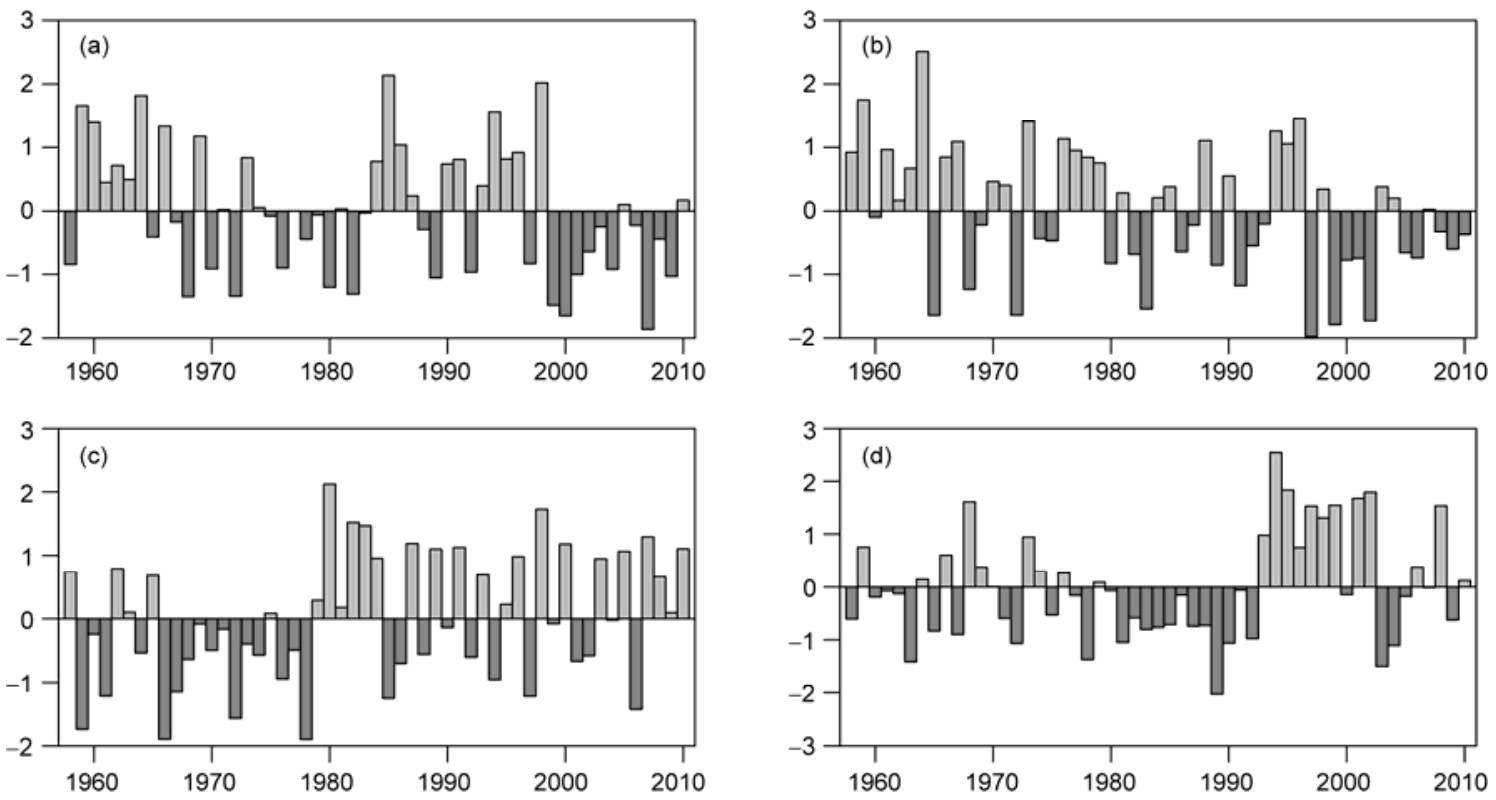

Figure 1 The normalized year-to-year precipitation anomaly percentages (\%) during boreal summer over the four regions (a) $\mathrm{NEC}\left(40^{\circ}-50^{\circ} \mathrm{N}\right)$, (b) $\mathrm{NC}$ $\left(35^{\circ}-40^{\circ} \mathrm{N}\right)$, (c) YHR $\left(30^{\circ}-35^{\circ} \mathrm{N}\right)$, and (d) SC $\left(20^{\circ}-30^{\circ} \mathrm{N}\right)$ in Eastern China.

and North China (NC, Figure 1(b)), and was above normal over the Yangtze-Huai River Valley (YHR, Figure 1(c)). Additionally, the summer precipitation over South China (SC, Figure 1(d)) during 1999-2010 was still above normal, but the magnitude was smaller than that during 1993-1998.

To more clearly display features of the interdecadal change of summer precipitation around the late-1990s over Eastern China, the 9-year-running-mean precipitation anomaly percentages are zonally averaged over the domain $100^{\circ}$ $120^{\circ} \mathrm{E}$ in Eastern China. As shown in Figure 2, on the interdecadal timescale, the precipitation variation prior to the 1990s in Eastern China presents a meridional triple pattern centered along the Yangtze River Valley, indicating the dominant role of the triple mode during this period. For the period 1990s, the anomalous precipitation pattern exhibits a uniform feature with positive anomalies, which suggests that, during the period, not only the triple mode but also the dipole mode plays an important role in the precipitation variability. However, since the late-1990s, the summer precipitation anomalous pattern shifts from the triple structure to the notable "south-positive-north-negative" dipole structure, which is coherent with Zhu et al. [13].

\subsection{The abrupt change of the summer precipitation over Eastern China around the late-1990s on the inter- decadal time scale}

The features of the interdecadal change around the late1990s, including location and associated precipitation change pattern, are also investigated using the moving $T$ test and Lepage test [24]. As shown in Figure 3, corresponding to this interdecadal change, the stations with significant precipitation

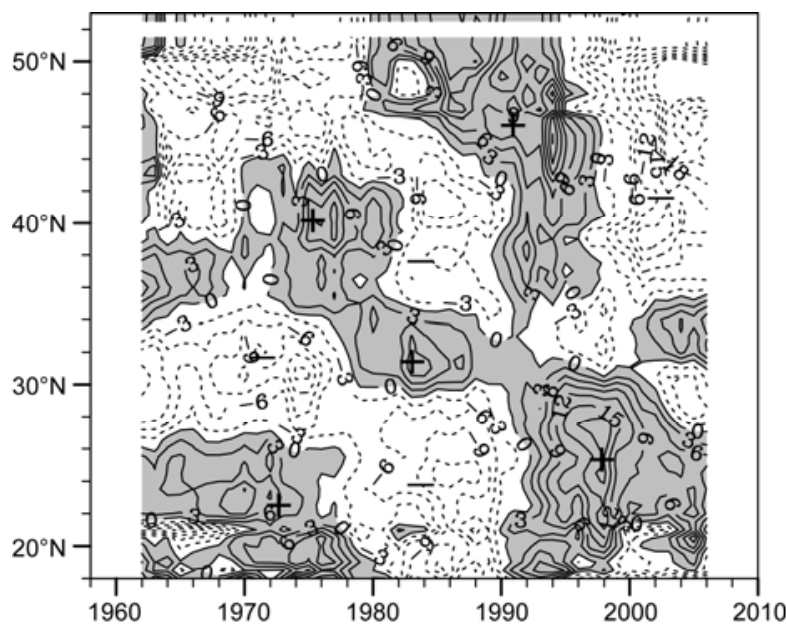

Figure 2 The cross section of latitude-time evolution of the 9-year-runningmean precipitation anomaly percentage $(\%)$ zonally-averaged over the domain $100^{\circ}-120^{\circ} \mathrm{E}$ in Eastern China. The solid (dash) line depicts precipitation anomalies above (below) normal, and shaded areas represent positive anomalies.

decrease above the $95 \%$ confidence level based on the Lepage test and moving $T$ test are mainly situated in the $\mathrm{NC}$ and NEC.

The above results indicate a robust interdecadal change of summer precipitation over Eastern China around the late-1990s. Accompanying this interdecadal change, the summer precipitation reveals an evident decrease over NEC and NC, increase over the Huai River Valley and SC. The precipitation anomaly pattern switched from the triple mode to the dipole mode, featuring the notable "south-flood-northdrought" structure except for the Yangtze River Valley. 



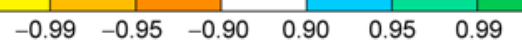

Figure 3 The summer precipitation differences (contour) between the period 1999-2010 and the 1971-2000. The solid (dash) line depicts precipitation anomalies above (below) normal. Shading and black dots denote areas and stations with precipitation anomalies beyond the $95 \%$ confidential significance level based on (a) Lepage test, (b) moving $T$ test, respectively.

\section{The interdecadal change of the dominant mode of the summer precipitation over Eastern China around the late-1990s}

To better illustrate the feature of the interdecadal precipitation change over summer monsoon region of Eastern China around the late-1990s, the present work further investigated the dominant modes of the summer precipitation anomalies by applying the EOF analysis to the observational precipitation dataset from 481 stations over Eastern China, and the first two dominant modes are given in this section.

\subsection{Meridional triple mode}

Figure 4(a) and (c) depicts the spatial-temporal features of the first EOF mode (EOF1). The spatial distribution of the EOF1 presents an obvious south-to-north ",,+-+ ," meridional triple structure. As for the corresponding time coefficiency (Figure 4(c)), we can observe that, since the mid1970s, the summer precipitation over Eastern China monsoon region exhibits a strong interannual variability with the period of about 2-3 years, showing a quasi-two-year oscillation, and it also reveals an evident interdecadal variability. The time series is positive during the period 1950 to mid/ late-1970s. In combination with Figure 4(a), this suggests that, during the above period, the summer precipitation is above normal over SC, NC, and south of NEC and below normal over YHR, and the precipitation anomalies feature a south-to-north "+, -, +" triple pattern. While opposite features are obtained during the period spanning from the $\mathrm{mid} / \mathrm{late}-1970 \mathrm{~s}$ to early-1990s (about 1978-1992), with south-to-north "-, +, -" anomalous precipitation distribution. As for the period 1993-1998, the time coefficiency is positive, and the associated precipitation anomalies reveal a south-to-north ",,+-+ " triple pattern, which is similar to that during 1958-1978. However, as shown in Figure 2, the precipitation anomalies during this period are characterized by precipitation increase over NC, and south of NEC, and evident increase with more floods over SC, while the summer precipitation over YHR does not decrease. These features suggest the role of the second mode of the summer precipitation anomaly over Eastern China monsoon region (Figure 4(b)). Besides, the time coefficiency related to EOF1 becomes small (Figure 4(c)) and that related to EOF2 (Figure 4(d)) large since 1999. This indicates that the dominant mode of the summer precipitation over Eastern China experience an interdecadal change around the late-1990s.

\subsection{Meridional dipole mode}

Figure 4(b) and (d) displays the spatial-temporal mode of the second principle component of the EOF analysis of summer precipitation over Eastern China during 1958-2010. On contrast to the spatial-temporal pattern of EOF1, the spatial mode of EOF2 shows a different structure having a south-to-north "+, -" meridional dipole pattern (Figure 4(b)). The time series related to EOF2 (Figure 4(d)) shows 3-4year interannual variability, and on the interdecadal time scale, its variability is much more obvious than that related to EOF1 since the late-1990s when the sign of the time series changes from negative to positive. In combination with Figure 4(b), these features suggest that the dominant modes of summer precipitation over Eastern China shifted from the triple pattern to the dipole pattern around the late-1990s, and anomalous precipitation reveal a "south-positive-northnegative" structure since then, namely "south-flood-northdrought".

Based on the above analysis in this section, we can conclude that the variability of the summer precipitation variability over Eastern China is dominated by both the triple and 

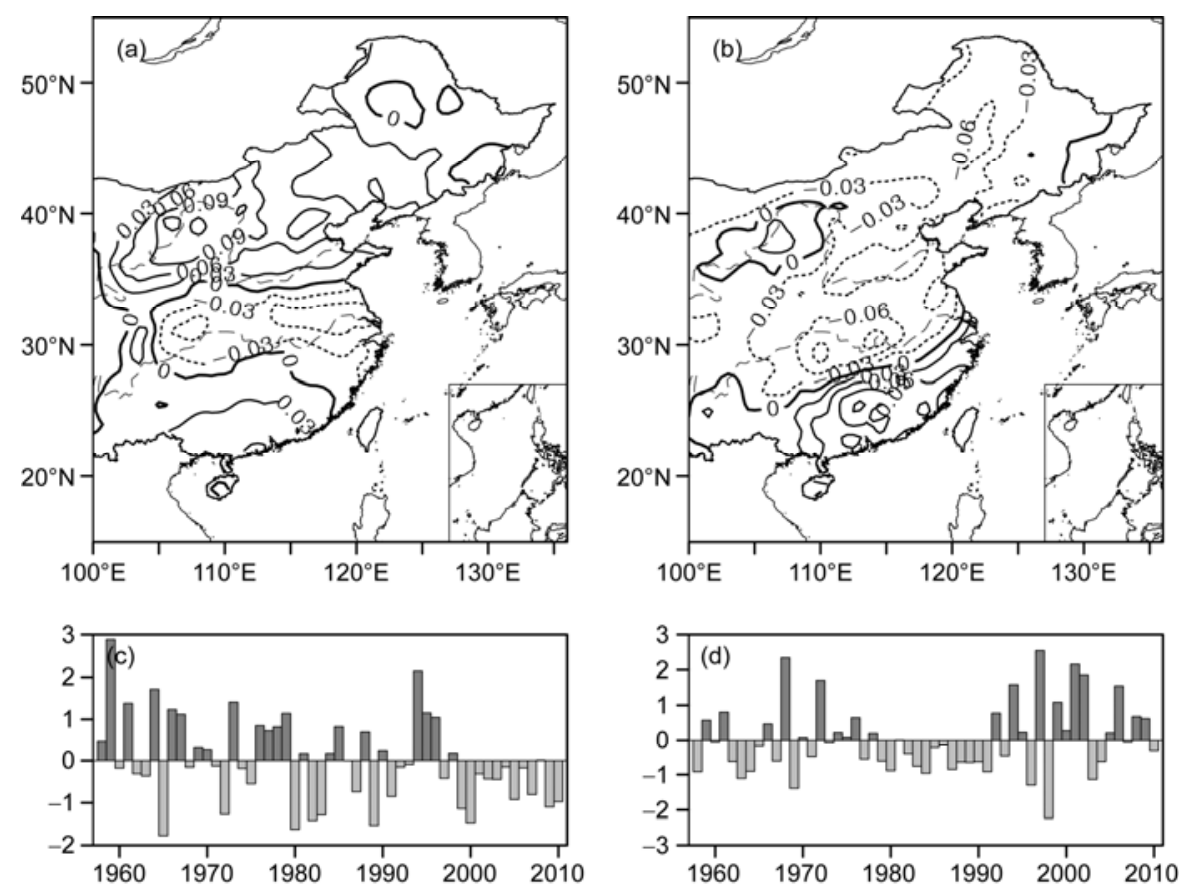

Figure 4 The first two principle components of the EOF analysis of the summer precipitation over Eastern China during 1958-2010. (a) and (b) Spatial pattern (EOF1, EOF2), (c) and (d) time coefficiency (PC1, PC2). The solid (dash) line denotes positive (negative) precipitation anomalies. And the contributions of EOF1 and EOF2 to the total variance accounts for $12.4 \%$ and $9.0 \%$, respectively.

dipole modes, which show large interannual and interdecadal variability. And at the late-1990s, the dominant mode switches from the triple mode to the dipole mode. This corresponds to the anomalous pattern of the summer precipitation over Eastern China.

\section{Interdecadal changes of the summer atmos- pheric circulation over East Asia during 1999- 2010 and its association with the precipitation variations over Eastern China}

The interdecadal change of summer precipitation over Eastern China around the late-1990s is accompanied by atmospheric circulation changes. Therefore, in this section, the interdecadal changes of the atmospheric circulation around the late-1990s are explored using the NCEP/NCAR reanalysis datasets, which include the winds and wind divergences at $200 \mathrm{hPa}$ and $700 \mathrm{hPa}$, vertical motion at $500 \mathrm{hPa}$, and the vertical integrated moisture transportation.

\subsection{The general atmospheric circulation anomalies over East Asia}

Figure 5(a) and (b) illustrates the differences of the horizontal winds and associated divergences at 700 and $200 \mathrm{hPa}$ levels between the mean of 1999-2010 and the climatology. It can be seen in Figure 5(a) that the low-level (700 hPa) wind anomalies feature an anomalous cyclone over SC and an anticyclone over Mongolia plateau and northern China (NC, NEC, and northwest China), showing a meridional dipole structure. Meanwhile, the corresponding wind divergences show a meridional dipole structure as well, with wind convergence over SC and divergence over Mongolia plateau and northern China. As for the circulation anomalies at $200 \mathrm{hPa}$ level shown in Figure 5(b), strong anomalous northeasterly is observed over Inner Mongolia, NEC and central and west part of NC, but anomalous southerly over the Yellow Sea, East Sea and Japan. The wind anomalies lead to wind divergence over SC and south of Yangtze River, and convergence over Inner Mongolia, NEC and central and west part of NC, showing a clear dipole mode which is out-of-phase to that at lower level. Owing to the meridional dipole structures in atmospheric circulation anomalies, the summer precipitation over Eastern China is enhanced over the Huai River Valley and SC and weakened over NEC, NC and east part of Northwest China, leading to the dipole pattern of summer precipitation anomalies over Eastern China.

\subsection{Vertical motion anomalies}

As indicated in 4.1, the atmospheric circulation at lower and upper levels revealed notable interdecadal changes around the late-1990s. It is conceived that the vertical motion also experienced interdecadal changes. Figure 6 depicts the differences of vertical motion at $500 \mathrm{hPa}$ between the mean of 1999-2010 and 1971-2000. The vertical motion anomalies display a dipole structure with ascent over Southern China 

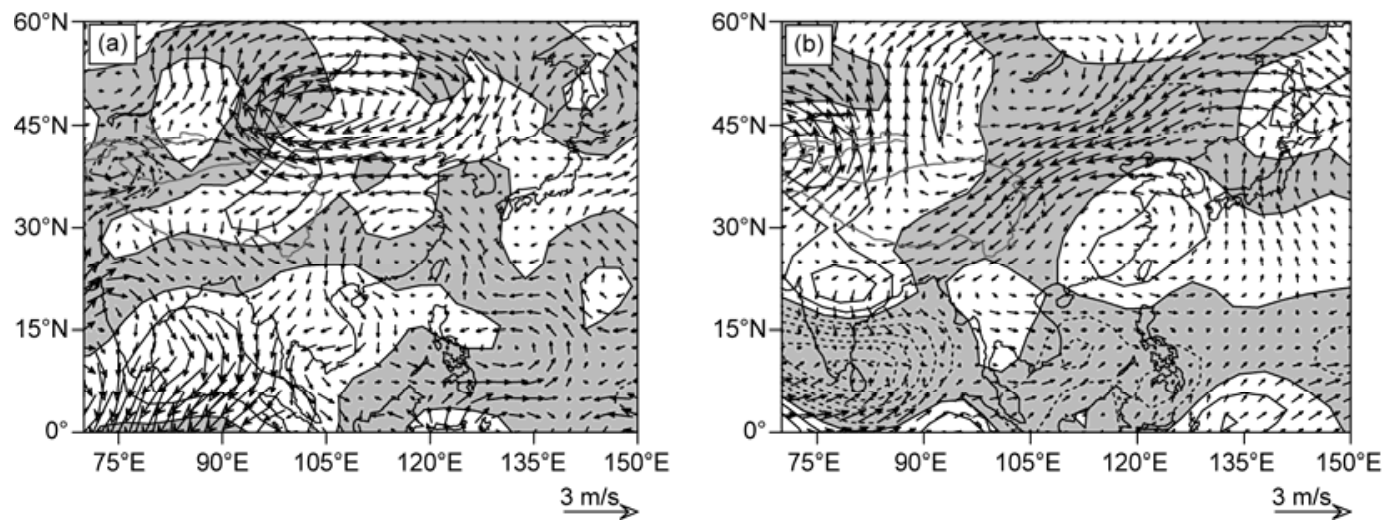

Figure 5 The difference of summer wind (vector, unit: $\mathrm{ms}^{-1}$ ) and associated divergence (contour, unit: $10^{-7} \mathrm{~s}^{-1}$ ) between the mean of 1999-2010 and 1971-2000, (a) $700 \mathrm{hPa}$ and (b) $200 \mathrm{hPa}$. The solid (dash) line represents wind divergence (convergence), and the convergence region is shaded.

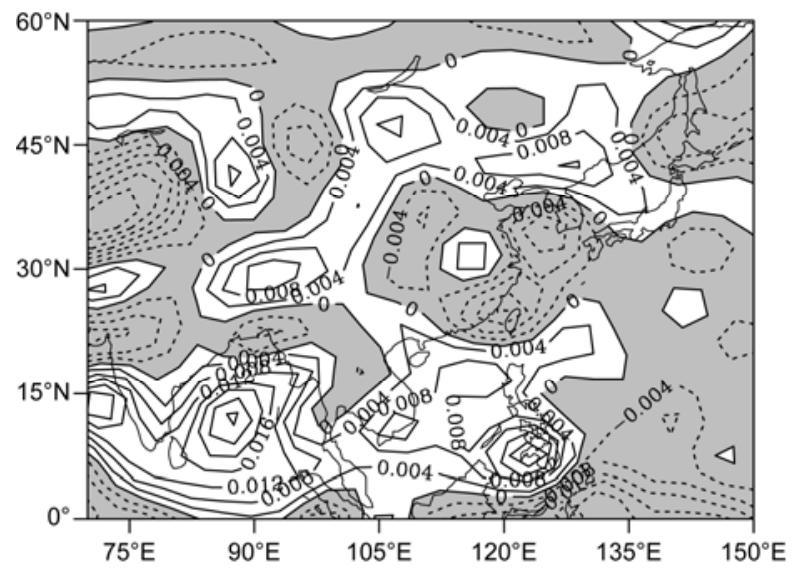

Figure 6 Like Figure 5 but for the vertical motion at $500 \mathrm{hPa}$ (unit: $10^{-5} \mathrm{hPa} \mathrm{s}^{-1}$ ). Shading denotes ascending motion.

and descent over Northern China. The anomalous dipole features of the vertical motion lead to a "south-flood-northdrought" anomalous dipole pattern of the summer precipitation during 1999-2010, bringing frequent floods to the YHR and persistent drought to NEC and NC.

The above results suggest that the interdecadal change of the summer precipitation over Eastern China around the late-1990s is related to the interdecadal changes of atmospheric circulation over East Asia.

\section{The internal dynamics causes for the interdecadal change of summer precipitation over Eastern China around the late-1990s}

The interdecadal change of the summer climate over East Asia is not only related to the interdecadal change of thermal forcing by the Pacific and Indian Ocean, but also to the internal variations of the atmospheric circulation over East Asia. Huang and Yan [25,26] documented that, forced by the same external forcing, the circulation and planetary wave propagation varied under different basic flow. Ac- companying the several interdecadal change of the summer precipitation over East Asia, the intensity and location of the subtropical upper-level westerly jet over East Asia exhibit notable interdecadal variations [11]. Thereby, the interdecadal change of the summer troposphere flow over East Asia may exert an important influence on the interdecadal change of summer climate over Eastern China. In this section, the internal dynamic role of interdecadal change of the troposphere mid-high level flow over East Asia in the interdecadal change of summer precipitation over Eastern China is investigated.

\subsection{The interdecadal change of the troposphere mid-high level zonal flow over East Asia}

Firstly, we analyzed the 9-year-running-mean zonal wind anomalies at $200 \mathrm{hPa}$ averaged over the domain $100^{\circ}-$ $140^{\circ} \mathrm{E}$. As shown in Figure 7(a), corresponding to the interdecadal change of summer precipitation over Eastern China, both the intensity and location of the subtropical upper-level westerly jet over East Asia reveal evident interdecadal changes. The zonal wind anomalies over East Asia feature a south-to-north ",,+-+ " triple structure prior to the mid/ late-1970s, and an opposite structure can be seen during the $\mathrm{mid} / \mathrm{late}-1970 \mathrm{~s}$ to the early-1990s. Since the late-1990s, the zonal wind anomalies show a south-to-north "+, -" dipole structure, which is evidently different from those prior to the early-1990s, indicating that the weakening and northward shift of the subtropical westerly jet over East Asia lead to a switch of the zonal wind anomalies over East Asia from the triple pattern to the dipole pattern. What's more, it also can be observed that, since the 1960s, the negative anomalies of zonal wind over East Asia and Northeast Asia move from high-latitude to middle-latitude, and meanwhile, the positive anomalies of the zonal winds over mid-latitude East Asia shift to subtropical and low-latitude regions.

The zonal wind anomalies at $500 \mathrm{hPa}$, on the interdecadal time scale, are also plotted in Figure 7(b). The features are well coherent with those at $200 \mathrm{hPa}$ (Figure 7(a)). 

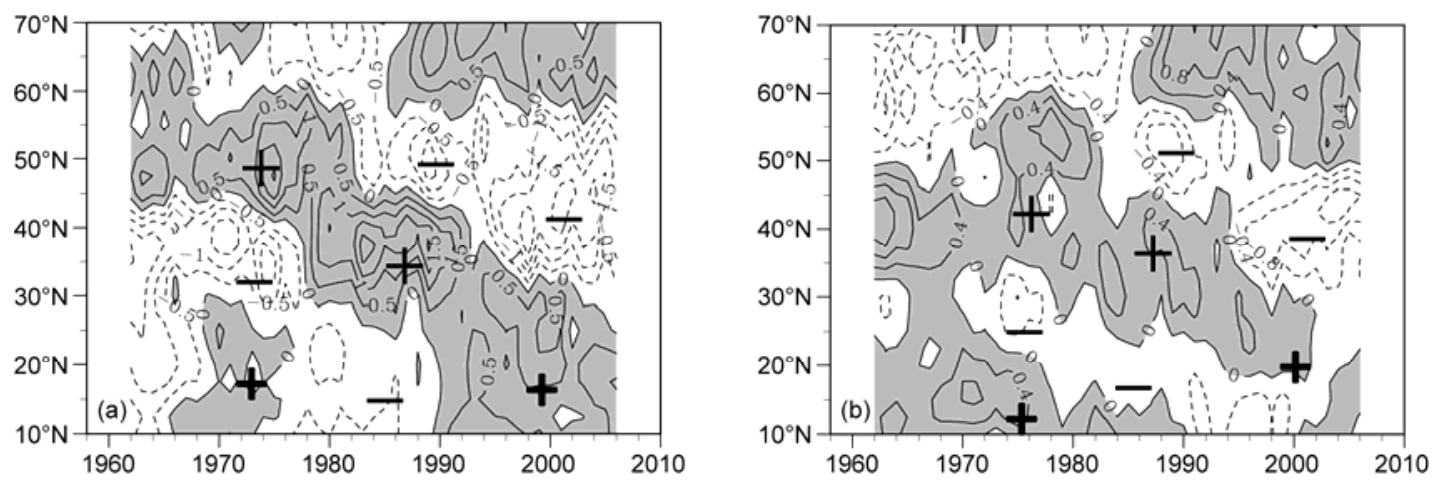

Figure 7 The cross section of latitude-time evolution of the 9-year-running-mean of the zonal wind anomaly (unit: $\mathrm{m} \mathrm{s}^{-1}$ ) zonally-averaged over the domain $100^{\circ}-140^{\circ} \mathrm{E}$ in East Asia. (a) $200 \mathrm{hPa}$; (b) $500 \mathrm{hPa}$. The solid (dash) line represents westerly (easterly) anomaly, and the westerly anomaly area is shaded.

From Figures 7 and 3, we can conclude that the meridional structure of the zonal wind anomalies at $200 \mathrm{hPa}$ and $500 \mathrm{hPa}$ over East Asia is consistent with that of the precipitation over Eastern China, and the dominant modes of the zonal winds and precipitation experienced an interdecadal change around the late-1990s, switching from the triple mode to the dipole mode. This suggests that the interdecadal change of the middle/upper troposphere flow during 1999-2010 exerts its role on the change of the low-level East Asia summer monsoon circulation, and further results in the interdecadal change of summer precipitation over East China.

\subsection{The dynamic role of the anomalous circulation over Eurasia on the moisture transportation over East- ern China during the northern summer of 1999-2010}

Huang et al. [8] pointed out that the interdecadal variability of summer precipitation over Eastern China is not only affected by the East Asia/Pacific pattern (EAP) teleconnection pattern [32-34], but also by the Eurasia (EU) pattern along the middle latitude westerly over Eurasia [35]. In addition, Lu et al. [27] documented that there existed a teleconnection pattern at the upper troposphere over Eurasia continent, which was named as "Silk Road" teleconnection pattern by Enomoto et al. [28] and Enomoto [29]. And recently, Chen and Huang [30] indicated that this teleconnection pattern showed great influence not only on the climate along its pathway, but also on the summer precipitation variation over Eastern China through its interaction with the EAP teleconnection pattern. The study of Kosaka et al. [31] suggested that the interannual variability of the Meiyu precipitation over East Asia is influenced by three teleconnection patterns including the "Silk Road" pattern along the upperlevel westerly jet, the EAP/PJ teleconnection pattern and the EU pattern along the polar jet. Therefore, the changes of the three teleconnection patterns during 1999-2010 definitely affect the variation of the Meiyu precipitation over East Asia.

It is clear that the lower and upper level atmospheric cir- culation over East Asia experienced obvious interdecadal changes during 1999-2010, which certainly will affect the moisture transportation over there. For a better understanding of the role of the three teleconnection patterns in the interdecadal change of summer precipitation over Eastern China, the present work investigated the interdecadal change of the moisture flux over Eurasia continent. The anomalies of the vertical integrated moisture flux from $1000-300 \mathrm{hPa}$ for the four periods 1958-1977, 1978-1992, and 1999-2010 and the 1971-2000 during boreal summer are given in Figure 8(a)-(d), respectively.

For the period 1958-1977, as shown in Figure 8(a), the anomalous moisture flux from South China, SC, YHR to NEC and Japanese Sea displays an "anticyclone-cycloneanticyclone" structure, which is similar to the EAP teleconnection pattern. And over the middle latitude of Eurasia continent, the moisture flux anomalies feature a "cycloneanticyclone-cyclone-anticyclone" pattern over the Caspian Sea, Mongolia Plateau, to Eastern China and Japanese Sea, resembling the "Silk Road" teleconnection pattern but with a northward shift, which may be due to the northward shifted westerly jet stream (Figure 7(a)). Meanwhile, a weaker and northward located EU-pattern-like moisture flux anomalies can be observed over the high latitude of the Eurasia continent. Additionally, we can see that strong northward moisture transportation distributes over Eastern China, suggesting a strong East Asia summer monsoon.

The moisture transportation anomalies during 1978-1992 (Figure 8(b)) exhibit opposite features to those during 19581977 (Figure 8(a)). A “cyclone-anticyclone-cyclone" EAPlike pattern exists over South China Sea, passing along Yangtze River Valley, NEC and Korean Peninsula to Okhotsk Sea. The moisture flux anomalies over the middle latitude Eurasia continent, from the Caspian Sea, passing along central Asia, northwest China and Inner Mongolia, to NEC, show "anticyclone-cyclone-anticyclone-cyclone" structure, similar to the "Silk Road" teleconnection pattern. And the anomalous wave-like center moves southward as the subtropical westerly jet enhanced on the equatorial side. Over the high latitude of the Eurasia continent, the EU-like 

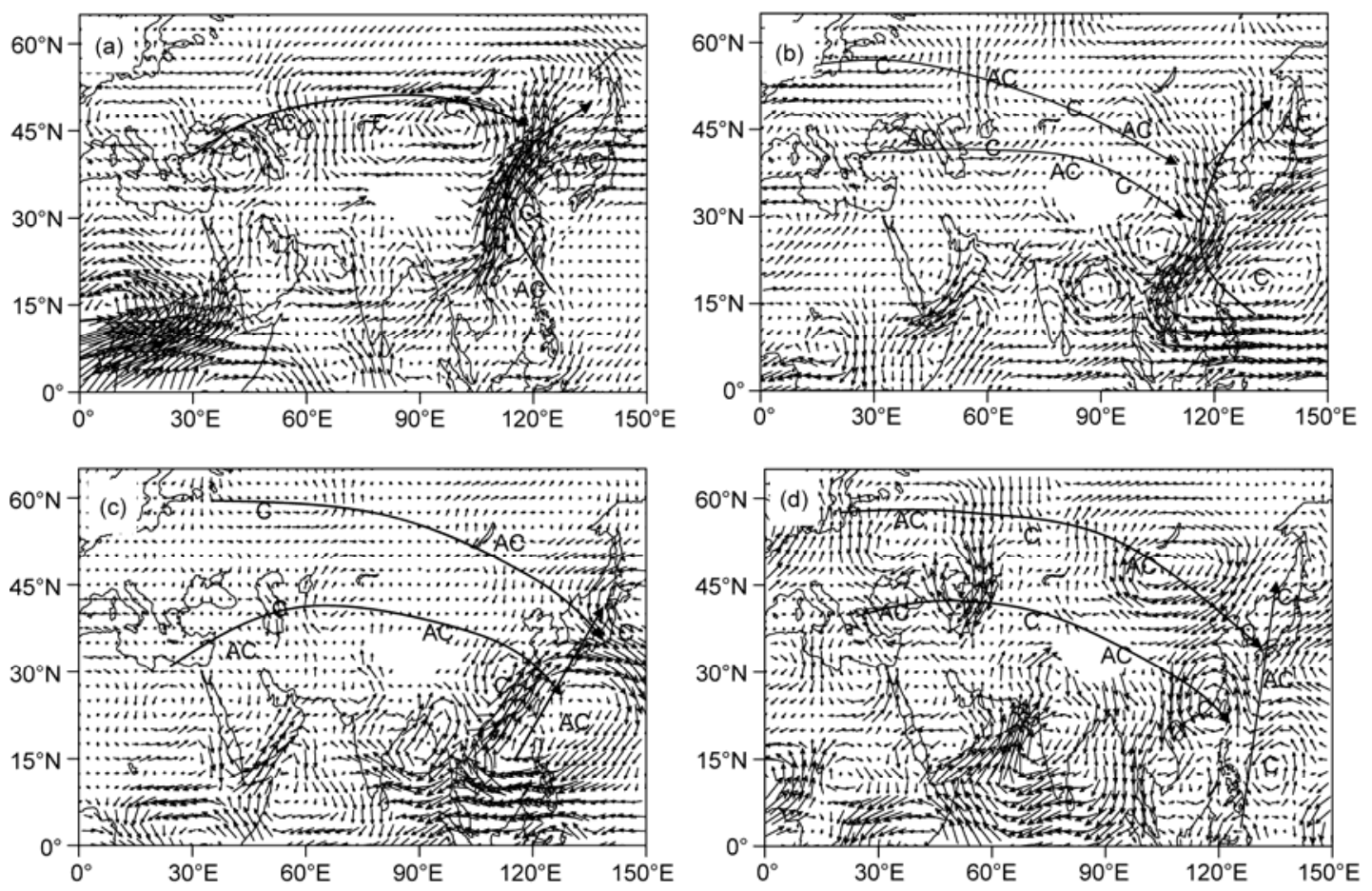

Figure 8 The differences of the summer moisture flux vertically integrated from 1000-300 hPa between the four periods (a) 1958-1977, (b) 1978-1992, (c) 1993-1998, (d) 1999-2010 and the climatology. The units of the vector in each plot are defined as 100, 40, 80 and $80 \mathrm{~kg} \mathrm{~m}^{-1} \mathrm{~s}^{-1}$, respectively.

anomalous moisture flux structure showing "cyclone-anticyclone-cyclone-anticyclone-cyclone" pattern from the northwest Europe, along Ural region and Mongolia Plateau to NEC, is clearer than that during 1968-1977. Likely, the anomalous southerly moisture transportation over East China implies a weaker East Asia summer monsoon during this period.

During 1993-1998, the anomalous features of the moisture flux reveal different characters from the former two periods. As shown in Figure 8(c), although the anomalous moisture flux over the middle/high latitude of Eurasia continent show features similar to those in Figure 8(a), the EU-pattern-like structure is not clear, suggesting that the moisture transportation from the Atlantic Ocean along the westerly jet is weaker. In addition, the anomalous moisture transportation features an "anticyclone-cyclone" structure from the South China Sea, through Eastern China and western north Pacific, to Japanese Sea and Japanese mainland. The strong northward moisture flux of the west flank of the anomalous anticyclone brings more moisture to Eastern China, Yellow Sea and East Sea, leading to positive precipitation anomalies during this period. The anomalous moisture flux over Eurasia continent along the westerly jet from Caspian Sea, central Asia to the northwest and Eastern China presents an "anticyclone-cyclone-anticyclone-cyclone" structure, resembling the "Silk Road" teleconnection pattern, and meanwhile, the wave-train centers shift southward as the westerly jet enhances at its south flank (Figure 7(a)). Furthermore, it can be seen that, during this period, the north- ward moisture transportation over Eastern China enhanced, indicating a strong East Asia summer monsoon.

The above results of the interdecadal change of the moisture flux over the Eurasia continent based on the NCEP/NCAR reanalysis dataset are something different from those based on the ERA-40 reanalysis dataset [8].

As for the period 1999-2010 (Figure 8(d)), the anomalous moisture flux over the middle/high latitude of Eurasia continent exhibits different features from that during the 1993-1998. There is a clearer EU-like pattern with anticyclonic moisture flux over northwest Europe, cyclonic moisture flux over Ural areas, and strong anticyclonic moisture flux over the Mongolia Plateau, NEC and NC. And for the East Asia, a cyclonic moisture flux over SC and an anticyclonic moisture flux over Northern China form a notable dipole structure. Meanwhile, we can clearly see that the "Silk Road"-like moisture flux distributed from Caspian Sea, Central Asia and northwest China to Central and Eastern China, which has an "anticyclone-cyclone-anticyclone-cyclone" pattern similar to that during 1993-1998. However, the cyclonic moisture flux over SC shifts eastward and the anticyclonic moisture flux is enhanced compared to that during 1993-1998, which leads to strong northerly moisture flux over Eastern China. These features indicate that the East summer monsoon is weak during 1999-2010, and the moisture flux to the NEC and NC, which is transported by the southwest summer monsoon from Bay of Bengal and through southwest China, is weak as well. Consequently, persistent drought with different degrees emerges over NC 
and NEC, and enhanced precipitation leads to severe floods over SC and the Huai River Valley.

As revealed in the results above, the interdecadal change of the summer precipitation over Eastern China around the late-1990s is largely related to the interdecadal changes of the three teleconnection patterns over Eurasia continent and western north Pacific Ocean, namely the EAP pattern extending northward from Philippines, the EU pattern along the polar jet stream, and the "Silk Road" pattern along the subtropical westerly jet stream.

\section{The thermodynamic role of the midtroposphere circulation anomalies over East Asia on the precipitation variation in Eastern China during the summers of 1999-2010}

Recent study of Sampe and Xie [36] indicated the advection of the warm and moist air from the eastern flank of the Tibetan Plateau triggered convective instability by inducing upward motion over southeastern China, which was further maintained by the plenty of moisture brought by the lowlevel circulation over the South China Sea and tropical western Pacific Ocean. And additionally, the ascent and convective instability were strengthened by synoptic transient eddy along the mid-latitude subtropical westerly jet. These factors favor the long-time maintaining of the Meiyu and lead to the summer precipitation variation over East Asia.

\subsection{The summer temperature advection anomalies at the mid-level troposphere over East Asia during 1999-2010}

The thermodynamic equation on the pressure $P$ coordinates can be written as

$$
\frac{\partial T}{\partial t}=\frac{Q}{C_{p}}-\overrightarrow{\mathrm{V}} \cdot \nabla T-\left(\frac{P}{P_{0}}\right)^{R / C_{p}} \cdot \omega \frac{\partial \theta}{\partial p},
$$

where $T$ is temperature, $\theta$ potential temperature, $\omega$ vertical velocity motion, $R$ gas constant, $C_{p}$ specific heat at constant pressure, $Q$ diabatic heating/cooling, $P_{0}$ sea level pressure and defined as $P_{0}=1000 \mathrm{hPa}$.

As the interdecadal climate variability is investigated in the present work, so the term $\frac{\partial T}{\partial t}$ in eq. (1) is small and thus can be ignored, and the horizontal temperature advection $(-\vec{V} \cdot \nabla T)$ also can be discussed on the monthly time scale. Besides, the domain of interest contains the middle latitude region and subtropics over which the magnitudes of the diabatic heating/cooling $Q$ are different. $Q$ is relative small over the middle latitude region. Although $Q$ is large over the subtropics, it is always highly related to the convection, namely vertical velocity $\omega$. Thus, an approximate balance between the vertical motion and horizontal temperature advection is concluded in eq. (1), namely

$$
\left(\frac{P}{P_{0}}\right)^{k} \omega \frac{\partial \theta}{\partial p} \propto-\vec{V} \cdot \nabla T,
$$

where $k=R / C_{p}$. Eq. (2) indicates that over the middle latitude region and subtropics, the region with a warm temperature advection corresponds to the region with ascending motion, and vice versa.

Following Sampe and Xie [36], the horizontal temperature advection is divided into the stationary and transient components, as shown below,

$$
\vec{V} \cdot \nabla T=\overline{\vec{V}} \cdot \nabla \bar{T}+\overline{\vec{V}^{\prime} \cdot \nabla T^{\prime}} .
$$

The first term of the RHS of eq. (3) denotes the horizontal temperature advection by stationary flow, the second term by the transient flow. Aiming to explore the thermodynamic role of the temperature advection at the middle troposphere on the upward motion over Eastern China, the summer temperature advection at $500 \mathrm{hPa}$ is computed using the monthly NCEP/NCAR reanalysis datasets, namely the term $(-\overline{\bar{V}} \cdot \nabla \bar{T})$ in eq. (3). Here, we analyze the timeevolution of 9-year-running mean of the temperature advection anomaly zonally averaged in the domain of $100^{\circ}-$ $140^{\circ}$ E over East Asia (Figure 9).

It can be seen from Figure 9 that since the early-1990s, the anomalous features of the temperature advection over the midtroposphere change from a meridional triple pattern to a dipole pattern. And in combination with Figure 7(a) and (b), accompanying the moving of the westerly anomalies over the middle/upper troposphere from mid-latitude to low-latitude, the warm temperature advection moves to low latitude as well, inducing cold temperature advection over northern China, and warm temperature advection over the YellowHuai River Valley and south part of SC (Figure 10(a)).

Likewise, the contribution of the temperature advection

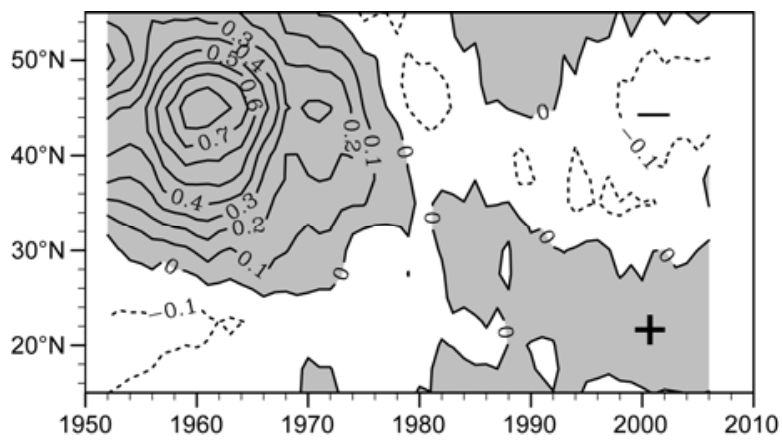

Figure 9 The cross section of latitude-time evolution of the 9-year-running mean of the summer temperature advection anomaly (unit: $\mathrm{K} \mathrm{d}^{-1}$ ), which is zonally averaged in the domain $100^{\circ}-140^{\circ} \mathrm{E}$ over East Asia. The solid (dash) line represents warm (cold) temperature advection, and the area with warm temperature advection is shaded. 

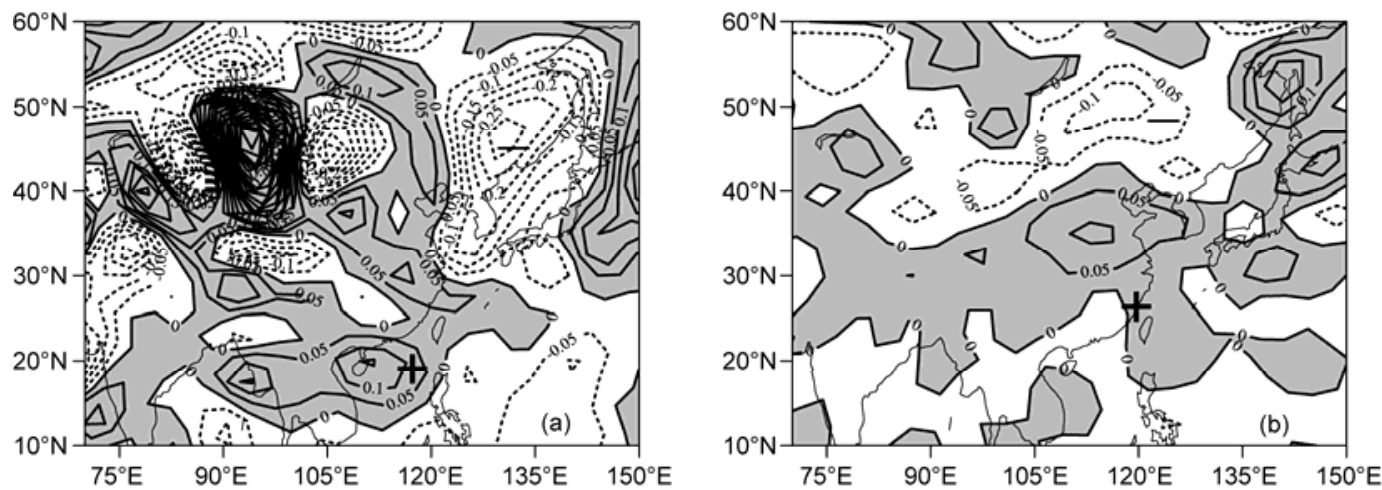

Figure 10 The differences of the summer temperature advection at $500 \mathrm{hPa}$ between the period 1999-2010 and 1971-2000. (a) Stationary component $(-\overline{\vec{V}} \cdot \nabla \bar{T})$, (b) transient component $\left(-\overline{\vec{V}^{\prime} \cdot \nabla T^{\prime}}\right)$. The unit is $\mathrm{K} \mathrm{d}^{-1}$. The warm temperature advection is shaded.

at midtroposphere by transient eddy (2-9 days scale) is also analyzed, namely the term $\left(-\vec{V}^{\prime} \cdot \nabla T^{\prime}\right)$. As shown in Figure 10(b), the temperature advection induced by the transient eddy shows similarity to that by stationary flow with a meridional dipole structure over Eastern China, but the magnitude of the temperature advection induced by the transient eddy is about a quarter of that by stationary flow.

\subsection{The relationship between the summer temperature advection at midtroposphere and vertical motion over East Asia during 1999-2010}

Sampe and Xie [36] documented a remarkable correspondence in the midtroposphere between the horizontal warm advection and upward motion during the Meiyu period, suggesting the role of the midtroposphere warm advection in the formation and maintenance of the Meiyu front. Consequently, the vertical motion can be deduced from the midtroposphere temperature advection.

Here, by comparing Figure 10 with Figure 6, we can obtain a good correspondence between the midtroposphere temperature advection and the vertical motion. The cold advection in Figure 10 associated with descent in Figure 6 situated over NEC, NC and northern part of northwest China, and the warm advection in Figure 10 related to ascent in Figure 6 located over Huai River Valley and northern SC. These features indicate that the interdecadal change around the late-1990s of middle/upper troposphere zonal wind anomaly from the triple pattern to the dipole pattern induces a switch of the temperature advection anomaly from the triple mode to the dipole mode, which triggers a dipole-like anomalous vertical motion, favoring the formation of the anomalous dipole mode of the summer precipitation over Eastern China, namely the "south-flood-north-drought" structure.

\section{Summary and discussion}

Using the observational precipitation datasets from detailed stations, the present study investigated the features of the interdecadal change of summer precipitation over Eastern China around the late-1990s through the methods of EOF, moving $T$ test and Lepage test. The results showed that the dominate mode of summer precipitation anomalies shifted from the triple pattern to the dipole pattern. Precipitation significantly decreased over NEC, NC and eastern part of northwest China and enhanced over south to the Huai River Valley with the exception along the Yangtze River. In addition, the atmospheric circulation changes corresponding to the interdecadal change are also explored with the NCEP/ NCAR monthly and daily reanalysis datasets. During the period 1999-2010, the atmosphere circulation anomalies over East Asia, including lower and upper-level winds and their divergence, midtroposphere vertical motion, feature a meridional dipole structure, corresponding well to the summer precipitation changes over Eastern China.

By analyzing the anomalous features of the moisture transportation, the present work also diagnosed the internal dynamic role of the dipole-like anomalies of the lower/upperlevel zonal flow during 1999-2010 (particularly the weakening and northward shift of the subtropical westerly jet stream) on the three teleconnection patterns over Eurasia continent, including the "Silk Road" pattern along the subtropical westerly jet, the EAP pattern over East Asia, and the EU pattern along the polar jet. Thus, from the perspective of interdecadal change of the stationary wave activity, the dynamic role of the middle/upper troposphere flow on the vertical motion change can be deduced. Meanwhile, based on the thermodynamic equation, the thermodynamic role of the midtroposphere zonal flow anomalies on the vertical motion and precipitation changes over East Asia is also studied by analyzing its role on the change of the temperature advection.

Because of the length limitation, the present study focuses on only the internal dynamic and thermodynamic role of the $\mathrm{mid} /$ high-level circulation anomalies on the interdecadal change of summer precipitation over Eastern China during 1999-2010. And we also find that the thermal forcing from 
the interdecadal change of the tropical Pacific and Indian Ocean sea surface temperature plays an important role in the interdecadal change of summer precipitation over Eastern China, which is confirmed by observational and numerical studies.

This work was supported by National Key Basic Research Program of China (2009CB421405, 2010CB950403), the Special Scientific Research Fund for Meteorological Public Welfare Profession of China (GYHY201006021) and the National Natural Science Foundation of China (41175055 and 40905027). The authors are grateful to Prof. Wu Renguang and the two anonymous reviewers for their insightful comments.

1 Chen L, Dong M, Shao Y. The characteristics of interannual variations on the East Asian monsoon. J Meteorol Soc Jpn, 1992, 70: 397 421

2 Ding Y H. Summer monsoon rainfalls in China. J Meteorol Soc Jpn, 1992, 70: 373-396

3 Huang R H, Xu Y H, Zhou L T. The interdecadal variation of summer precipitation in China and the drought trend in North China (in Chinese). Plateau Meteorol, 1999, 18: 465-477

4 Huang R H, Zhou L T, Chen W. The progresses of recent studies on the variabilities of the East Asian monsoon and their causes. Adv Atmos Sci, 2003, 20: 55-69

5 Huang R H, Chen W, Zhang R H. Recent advances in studies of the interaction between the East Asian winter and summer monsoons and ENSO cycle. Adv Atmos Sci, 2004, 21: 407-424

6 Ding Y H, Chan J C L. The East Asian summer monsoon: An overview. Meteorol Atmos Phys, 2005, 89: 117-142

7 Huang R H, Chen J L, Huang G. Characteristics and variations of the East Asian monsoon system and its impacts on climate disasters in China. Adv Atmos Sci, 2007, 24: 993-1023

8 Huang R H, Chen J L, Liu Y. Interdecadal variation of the leading modes of summertime precipitation anomalies over Eastern China and its association with water vapor transport over East Asia (in Chinese). Chin J Atmos Sci, 2011, 35: 589-606

9 Yamamoto R, Iwashima T, Songa N K, et al. An analysis of climatic jump. J Meteorol Soc Jpn, 1986, 64: 273-281

10 Yan Z, Ji J, Ye D. Northern hemispheric summer climatic jump in the 1960s. Part I: Precipitation and temperature. Sci China Ser B, 1990, 33: 97-103

11 Kwon M H, Jhun J G, Ha K J. Decadal change in East Asian summer monsoon circulation in the mid-1990s. Geophys Res Lett, 2007, 34: L21706

12 Ding Y H, Wang Z Y, Sun Y. Interdecadal variation of the summer precipitation in East China and its association with decreasing Asian summer monsoon. Part I: Observed evidences. Int J Climatol, 2008, 28: $1139-1161$

13 Zhu Y, Wang W, Zhou W, et al. Recent changes in the summer precipitation pattern in East Asia and the background circulation. Clim Dyn, 2010, 36: 1463-1473

14 Gong D Y, Ho C H. Shift in the summer rainfall over the Yangtze River valley in the late 1970s. Geophys Res Lett, 2002, 29: 1436

15 Xie S P, Hu K M, Hafner J, et al. Indian Ocean capacitor effect on Indo-western Pacific climate during the summer following El Niño. J Clim, 2009, 22: 730-747
16 Li S L, Lu J, Huang G, et al. Tropical Indian Ocean basin warming and East Asian summer monsoon: A multiple AGCM study. J Clim, 2008, 21: 6080-6088

17 Huang G, Liu Y, Huang R H. The interannual variability of summer rainfall in the arid and semiarid regions of Northern China and its association with the northern hemisphere circumglobal teleconnection. Adv Atmos Sci, 2011, 28: 257-268

18 Yu R C, Wang B, Zhou T J. Tropospheric cooling and summer monsoon weaking trend over East Asia. Geophys Res Lett, 2004, 31: L22212

19 Yu R C, Zhou T J. Seasonality and three-dimensional structure of interdecadal change in the East Asian monsoon. J Clim, 2007, 20: 5344-5355

20 Ding Y H, Sun Y, Wang Z Y, et al. Inter-decadal variation of the summer precipitation in China and its association with decreasing Asian summer monsoon. Part II: Possible causes. Int J Climatol, 2009, 29: 1926-1944

21 Wu R G, Wen Z P, Yang S, et al. An interdecadal change in southern China summer rainfall around 1992/93. J Clim, 2010, 23: 2389-2403

22 Kalnay E, Kamamitsu M, Kistler R, et al. The NCEP/NCAR 40-year reanalysis project. Bull Amer Meteorol Soc, 1996, 77: 437-471

23 Lepage Y. A combaination of Wilecoxon's and Ansar-Bradley's statistics. Biometrika, 1971, 58: 213-217

24 Liu Y, Huang G, Huang R H. Inter-decadal variability of summer rainfall in Eastern China detected by the Lepage test. Theor Appl Climatol, 2011, 106: 481-488

25 Huang R H, Yan B L. Influence of the basic flow in the tropics on the stationary planetary waves at middle and high latitudes during the Northern Hemisphere winter. Acta Meteorol Sin, 1989, 3: 437-447

26 Huang R H, Yan B L, Gambo K. Role of basic flow in influence of ENSO on winter circulation over the Northern Hemisphere (in Chinese). Chin J Atmos Sci, 1991, 15: 44-53

27 Lu R Y, Oh J H, Kim B J. A teleconnection pattern in upper-level meridional wind over the North African and Eurasian continent in summer. Tellus, 2002, 54A: 44-55

28 Enomoto T, Hoskins B J, Matsuda Y. The formation mechanism of Bonin high in August. J Roy Meteorol Soc, 2003, 129: 157-178

29 Enomoto T. Interannual variability of the Bonin high as associated with the propagation of Rossby waves along the Asian jet. J Meteorol Soc Jpn, 2004, 82: 1019-1024

30 Chen G S, Huang R H. Excitation mechanism of the teleconnection patterns affecting the July precipitation in Northwest China. J Clim, 2012, 25: 7834-7851

31 Kosaka Y, Xie S P. Nakamura H. Dynamics of interannual variability in summer precipitation over East Asia. J Clim, 2011, 24: 5435-5453

32 Nitta T. Convective activities in the tropical western Pacific and their impact on the Northern Hemisphere summer circulation. J Meteorol Soc Jpn, 1987, 64: 373-400

33 Huang R H, Li W J. Influence of the Heat source anomaly over the tropical western Pacific on the Subtropical high over East Asia. Proceedings of International Conference on the General Circulation of East Asia, 10-15 April, 1987. 40-51

34 Huang R H, Li W J. Influence of heat source anomaly over the western tropical Pacific on the subtropical high over East Asia and its physical mechanism (in Chinese). Chin J Atmos Sci, 1988, 12(s1): 107-116

35 Wallace J M, Gutzler D S. Teleconnection in the geopotential height field during the Northern Hemisphere winter. Mon Weather Rev, 1981, 100: 748-812

36 Sampe T, Xie S P. Large-scale dynamics of the Meiyu-Baiu rainband: Environmental forcing by the westerly jet. J Clim, 2010, 23: 113-134

Open Access This article is distributed under the terms of the Creative Commons Attribution License which permits any use, distribution, and reproduction in any medium, provided the original author(s) and source are credited. 